\title{
When Prone Position Is Contraindicated Or Not Preferable, Can Supine Percutaneous Nephrolithotomy Solve The Problem?
}

\author{
A. Youssef, M. Esmat, M. Wael \\ Urology Department, Ain Shams University, Cairo, Egypt
}

\section{ABSTRACT}

Purpose: To assess safety and efficacy of supine percutaneous nephrolithotomy in patients for whom prone position or general anesthesia is contraindicated or not preferable due to associated comorbidities, overweight or ipsilateral upper ureteric calculi.

Materials and Methods: Fifty two patients (37 males and 15 females, mean age 33 \pm 10.2 years) were included in this study. Supine position was selected due to anesthetic considerations (preexisting compromised cardiopulmonary status, morbid obesity (body mass index $>40 \mathrm{~kg} / \mathrm{m}^{2}$ ) and/or other associated medical comorbidities), impossible prone position due to bone deformities or associated ipsilateral upper ureteric stone. Regional anesthesia was used in 24 patients while 28 patients underwent general anesthesia. After standard cystoscopy and retrograde ureteropyelography in the dorsal lithotomy position, the position was modified using 3 liters of saline bag below the ipsilateral upper flank. Percutaneous access to the pelvicalyceal system was performed through the posterior axillary line under fluoroscopic guidance.

Results: Successful renal puncture was achieved in all cases. Single access via the lower calyx was the most commonly used access (36 cases). Stone-free rate was 92.3\%. Postoperative complications classified according to Clavien Dindo classification included bleeding requiring transfusion (3.8\%), prolonged fever (7.7\%), deep venous thrombosis (1.9\%) [grade II in all] and urinary leakage requiring ureteric stenting (5.8\%) [grade IIIa].

Conclusions: The modified supine position for percutaneous nephrolithotomy is a safe and effective option that offers several advantages with an excellent outcome. It can be performed safely for morbidly obese patients and those with cardiopulmonary compromise.

\section{ARTICLE INFO}

\section{Key words:}

Kidney calculi; Percutaneous nephrolithotomy; Supine

position

Int Braz J Urol. 2012; 38: 57-62

Submitted for publication:

February 12, 2011

Accepted after revision:

July 27,2011

\section{INTRODUCTION}

Percutaneous nephrolithotomy (PCNL) is an established modality for treatment of large renal calculi. Fernstrom and Johanson were the first to remove a renal stone through the nephrostomy tract in 1976 (1). Traditionally, PCNL has been performed in the prone position as it was thought to be the safest approach to the kidney. However, this position has some limitations including associated restricted ventilatory capacity (2), circulatory difficulties and increased intraocular pressure (3) which make it 
risky especially in patients with compromised cardiopulmonary status and morbid obesity or even impossible due to some bone deformities (4).

Various modifications of patient positioning for PCNL were reported including supine (5), lateral decubitus (flank) (6), split-leg (7) and reverse lithotomy (8) positions. All of them were reported to be safe and effective compared with the original prone PCNL.

Although supine PCNL was described by Valdivia et al. (5) several years ago, it did not gain wide distribution in comparison to prone PCNL in some urologic centers most probably due to fear of visceral injury. In this study, we evaluated the safety and efficacy of supine PCNL in patients in whom prone position was risky or not preferable.

\section{MATERIALS AND METHODS}

Between March 2008 and June 2009 at Ain Shams University hospital, Cairo, Egypt, 52 patients (37 males and 15 females) who underwent PCNL in the supine lithotomy position were prospectively included in this study. Their mean age was $33 \pm 10.2$ (range 21-63 years). Inclusion criteria included patients with single or multiple renal stones $\geq 2 \mathrm{~cm}$ or $>1.5 \mathrm{~cm}$ in lower calyx for whom supine PCNL was preferred due to anesthetic considerations, impossible prone position (due to bone deformities) or associated ipsilateral upper ureteric calculi. Patients with uncontrolled coagulopathies or aged less than 12 years were excluded from this study. Stone characteristics are shown in Table-1.

Preoperative evaluation included history taking, clinical examination and basic laboratory investigations. Patients with a positive urine culture were treated by a proper antibiotic for one week before the operation. Radiological investigations included abdominal plain X-ray (KUB), pelvi-abdominal ultrasonography and computerized tomography (CT) for all patients. Preoperative stone size was determined by measuring the stones longest diameter on KUB film. In cases with multiple stones, stone size was determined by the sum of each stone diameter on abdominal plain X-ray film (9).
Table 1 - Stone characteristics.

\begin{tabular}{lc}
\hline Number & $1-6$ \\
\hline Stone Size (mm) & $372 \pm 9.5(233-561)$ \\
Right - left side & $38-14$ \\
Site & \\
Renal pelvis & 36 \\
Calyceal (lower, middle) & 12 \\
Staghorn stone & 4 \\
Associated stone & \\
Upper ureter & 5 \\
Ipsilateral lower ureter & 3 \\
Contralateral lower ureter & 1 \\
\hline
\end{tabular}

The study was approved by the Ain Shams University Ethical Committee. Preoperatively, an informed consent was obtained from all patients.

\section{Procedure}

Twenty eight patients underwent general anesthesia while 24 patients underwent regional anesthesia (17: high spinal and 7: epidural anesthesia).

Patients were placed in the dorsal lithotomy position. After standard cystoscopy, retrograde ureteropylography was done under fluoroscopic guidance (C-arm). In the presence of associated ipsilateral upper ureteric stone, an attempt was made to push it into the pelvicalyceal system. Surface marking of the lower rib and iliac crest were done (Figure-1). The position was then modified using $3 \mathrm{~L}$ saline bag below the ipsilateral upper flank so that the posterior axillary line was 45 degrees to horizontal and the contralateral arm was adducted to the side of patient.

Percutaneous access to the pelvicalyceal system was performed through the posterior axillary line under fluoroscopic guidance while tract dilatation was performed using serial metal Alken dilators. Following serial telescopic dilatation, a 30 Fr. Amplatz sheath was positioned 
allowing the introduction of a 26 Fr nephroscope (Figure-2).

Nephroscopy and stone fragmentation and retrieval were carried out in the usual fashion as in the prone position. Small stones were directly extracted by a grasper and large stones were fragmented using Swiss lithoclast.

A nephrostomy tube (22 Fr) was inserted at the end of the procedure in 46 patients, while in 6 patients (with single stones, achieving complete

Figure 1 - Surface marking of the lower rib, iliac crest and posterior axillary line.

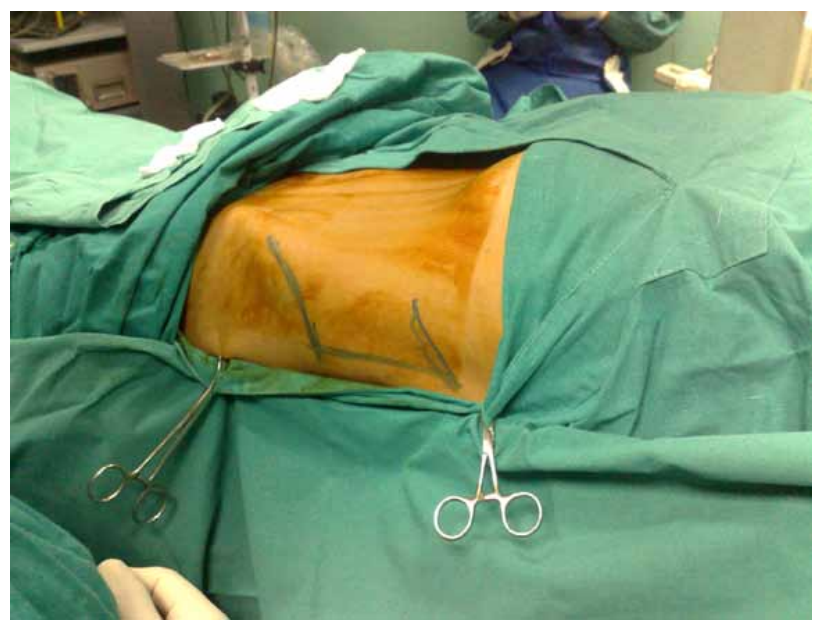

stone clearance with no intraoperative bleeding) the procedure was carried out in a completely tubeless fashion.

Operative time was determined by estimating the time between the application of ureteric catheter till placement of the nephrostomy tube (or the skin closure of nephrostomy site in tubeless cases).

Kidney, ureter and bladder (KUB) X-rays were performed to detect any residual significant stone on the first day postoperatively to do a second look PCNL if needed while ultrasound scans were performed to detect any residual radiolucent stone and other complications such as hematoma and extravasation.

The nephrostomy tube was removed 24 hours postoperatively if stone clearance was judged to be satisfactory. Patients were then monitored for the following 24 hours and the urethral and ureteric catheters were removed. Finally, patients were discharged provided being afebrile and with no leakage from the nephrostomy site.

Patients with residual stones $\leq 4 \mathrm{~mm}$ on abdominal plain X-ray (KUB) or ultrasonography 2 weeks postoperatively were considered stone-free.

Patient characteristics, stone size and locations, operative time, length of hospital stay, stone free rate, complications and need of auxiliary procedure post PCNL were recorded.

\section{RESULTS}

Among the 52 studied patients, prone position was contraindicated in 31 patients, of whom 16 suffered chronic obstructive airway disease (COAD) with abnormal pulmonary function tests, 5 had significant cardiac decompensation, 8 were morbidly obese (body mass index $>40 \mathrm{~kg} / \mathrm{m}^{2}$ ) according to WHO classification of obesity (10). The remaining 2 patients had severe skeletal deformities (rheumatoid arthritis) for whom it was technically impossible to use the conventional prone position. Supine position was also preferred in 5 patients who had associated ipsilateral upper ureteric stones, and for 16 patients due to their associated comorbidities or overweight.

Ureteroscopy and stone retrieval for lower ureteric stones was done in 4 cases prior to PCNL (3 ipsilateral side and 1 contralateral side).

Figure 2 - Amplatz sheath was positioned after tract dilatation.

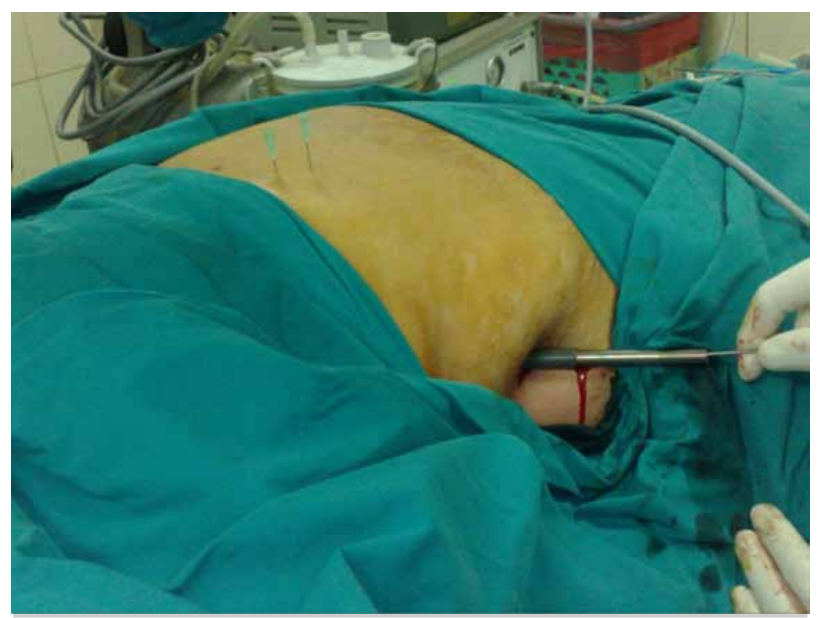


All cases were punctured successfully with easy access to the pelvicalyceal system while being in the supine position. In morbidly obese patients, long nephroscope $(26 \mathrm{~cm})$ and long amplatz sheath $(21 \mathrm{~cm})$ were needed to reach the collecting system. One of them also needed mini laparotomy through the skin and superficial fatty layer and the puncture was done at the deep fascia. Single access via the lower calyx was the most commonly used access (36 cases). Single middle calyx puncture was done in 6 cases ( 5 for middle calyceal stones and 1 for impacted upper ureteric stones). Double puncture (lower \& middle calyces) was done in 3 cases presenting with staghorn stones.

Simultaneous ureteroscopy was done in one female patient with an impacted ipsilateral upper ureteric stone to disintegrate the stone and complete stone clearance was achieved.

The operative time ranged from 27 to 134 minutes with a mean operative time of $46 \pm 16$ minutes. The mean length of hospital stay was $5 \pm$ 0.5 days (ranged: 4 to 8 days).

Complete clearance of significant stone fragments was achieved in 48 cases (92.3\% stonefree rate). Four cases were left with residual stones $>4 \mathrm{~mm}, 2$ of whom were managed successfully by second look nephroscopy during the first week postoperatively. The other 2 had calyceal stones that were difficult to be extracted by the nephroscope so they were managed by extracorporeal shock-wave lithotripsy (ESWL).

With regards to the complications (Table-2) and with application of Clavien-Dindo classification of surgical complications (11), we found that two patients (3.8\%) required blood transfusion (grade II). Post operative fever of $>38^{\circ} \mathrm{C}$ lasting for $\geq 2$ days and requiring a full course of antibiotics was observed in 4 patients (7.7\%) (grade II). One patient (1.9\%) experienced post operative deep venous thrombosis of the lower limb (grade II). Three cases (5.8\%) required secondary ureteric stenting for prolonged urinary leakage from the site of nephrostomy tube (grade IIIa).

None of our patients suffered pleural injury, colonic injury or any visceral injuries and none of them required a conversion to open surgery.
Table 2 - Complications.

$\begin{array}{lc}\text { Bleeding requiring blood transfusion } & 2(3.8 \%) \\ \text { Prolonged fever } & 4(7.6 \%) \\ \text { Deep venous thrombosis } & 1(1.9 \%) \\ \text { Reoperation } & 7(13.4 \%) \\ \quad \text { Ureteric stenting } & 3(5.7 \%) \\ \text { Second look PCNL } & 2(3.8 \%) \\ \text { ESWL for residual stones } & 2(3.8 \%)\end{array}$

\section{DISCUSSION}

Prone position is associated with respiratory or ventilatory difficulties which causes a decreased functional residual capacity of the lung, decreased expiratory lung volume and total lung capacity (12) and these changes are further increased with the general anesthesia. Such problems deprived certain categories of patients e.g. morbidly obese patients and patients with compromised pulmonary or cardiac function from performing PCNL. Also, patients with severe bone deformities which made the prone position impossible to be applied share the same problem. In our series, we used the supine position which enabled us to perform PCNL for all these patients' categories with excellent outcome. This was also achieved by performing the procedure under regional anesthesia in 24 patients (16 of whom had respiratory distress and abnormal pulmonary function) as the patients felt comfortable during supine position in contrast to prone position in which the patients could not withstand the procedure.

Beside these anesthetic advantages, we observed other significant proponents of supine PCNL in our series. The most clear one was the maintenace of the patient's position during the procedure which saved time and effort, decreased the incidence of limb or neck injury or dislocation of endotracheal tube and provided a better control of airway. Also, we observed that dependant drainage of the Amplatz sheath facilitated the 
clearance of small stone fragments as recorded by other studies $(5,7)$. Moreover, this position allowed simultaneous ureteroscopy to be performed which was beneficial in one case with impacted upper ureteric stone.

On the other hand, some limitations with supine position were encountered. The first was the medial displacement and greater mobility of the kidney at the step of renal puncture. This fact, in addition to the more lateral skin puncture site compared to the prone position, made necessary the use of a long nephroscope and long amplatz sheath essential for some cases especially obeses. The second limitation was the upper polar puncture which was difficult and challenging because of the upper calyx's anatomical considerations being more medial, posterior and concealed deeply in the rib cage. We did not attempt puncturing the upper calyx in the supine position; whenever needed, we reached it through the lower calyx. Another non-significant disadvantage observed during supine PCNL was that the pelvicalyceal system is constantly collapsed which may affect the surgeon's view, but this was overcomed by tilting the table toward the contralateral side.

Stone-free rate was calculated in this study considering fragments $\leq 4 \mathrm{~mm}$ as non-significant. We achieved good results with a stone free rate in $92.3 \%$ of cases (48 patients). The remaining 4 patients with residual stones were managed successfully by a second look nephroscopy in two of them and extracorporeal shockwave lithotripsy (ESWL) for the other two. Other studies also reported comparable stone-free rates with supine position where Denbysteele reported complete clearance of significant stone fragments in 91\% of cases (13), while Shoma and colleagues reported stone clearance rate of $89 \%$ in the supine position (14).

In our series, no major complications occurred. The rate of blood transfusion was 3.8\% which is comparable to the other published series; Shoma and colleagues reported a bleeding rate of 9\% in the supine position (14) while Manohar and colleagues reported a bleeding rate of 3.2\% (15) and in Valdivia's series it was 1.4\% (5). Other complications included prolonged fever in 4 patients (7.6\%), deep venous thrombosis in one pa- tient (1.9\%) and three patients (5.7\%) needed ureteric stenting for prolonged urinary leakage while visceral injury was not encountered in our series. Some authors prefer to do renal puncture under ultrasonographic guidance for supine PCNL for fear of colonic injury (15). In our series, preoperative pelvi-abdominal computerized tomography was done for all patients to recognize the anatomical relations of the kidney and to detect radiolucent calculi. We used the posterior axillary line as the site of puncture and sometimes slightly anterior to it according to Valdivia et al. (5) but in contrast to $\mathrm{Ng}$ et al. (16) who preferred the anterior axillary line. We suggested that the use of preoperative computed tomography and the more posterior site of skin puncture (at the posterior axillary line) decrease the incidence of colonic injury. Both LeRoy et al. (17) and Hopper et al. (18) found that only $2 \%$ of their patients had retro renal colon when supine which subsequently increased to $10 \%$ when prone. Valdivia et al. (5) reported that the colon was more distant from the kidney in the supine position in comparison to the prone position after performing renal puncture in the supine position in human corpses. While in most of the published series there haven't been colon injuries as it has been reported by Reddy et al. (19) (one colonic injury in 400 patients), and in the study by Segura et al. (20) (two colonic injuries were reported in 1.000 patients). Accordingly, we found that the incidence of colonic injury is extremely rare and it should not be a reason to neglect supine PCNL.

\section{CONCLUSIONS}

The supine PCNL is an effective and safe procedure which carries out several advantages. It can be done under regional anesthesia which makes it suitable for patients who have a contraindication to prone position or to general anesthesia including morbidly obese patients or those with cardio-pulmonary compromise.

\section{CONFLICT OF INTEREST}

None declared. 


\section{REFERENCES}

1. Fernström I, Johansson B: Percutaneous pyelolithotomy. A new extraction technique. Scand J Urol Nephrol. 1976; 10: 257-9.

2. Peces-Barba G, Rodríguez-Nieto MJ, Verbanck S, Paiva M, González-Mangado N: Lower pulmonary diffusing capacity in the prone vs. supine posture. J Appl Physiol. 2004; 96: 1937-42.

3. Cheng MA, Todorov A, Tempelhoff R, McHugh T, Crowder $\mathrm{CM}$, Lauryssen $\mathrm{C}$ : The effect of prone positioning on intraocular pressure in anesthetized patients. Anesthesiology. 2001; 95: 1351-5.

4. de la Rosette JJ, Tsakiris P, Ferrandino MN, Elsakka AM, Rioja J, Preminger GM: Beyond prone position in percutaneous nephrolithotomy: a comprehensive review. Eur Urol. 2008; 54: 1262-9.

5. Valdivia Uría JG, Valle Gerhold J, López López JA, Villarroya Rodriguez S, Ambroj Navarro C, Ramirez Fabián M, et al.: Technique and complications of percutaneous nephroscopy: experience with 557 patients in the supine position. $J$ Urol. 1998; 160: 1975-8.

6. Kerbl K, Clayman RV, Chandhoke PS, Urban DA, De Leo BC, Carbone JM: Percutaneous stone removal with the patient in a flank position. J Urol. 1994; 151: 686-8.

7. Scarpa RM, Cossu FM, De Lisa A, Porru D, Usai E: Severe recurrent ureteral stricture: the combined use of an anterograde and retrograde approach in the prone split-leg position without X-rays. Eur Urol. 1997; 31: 254-6.

8. Lehman T, Bagley DH: Reverse lithotomy: modified prone position for simultaneous nephroscopic and ureteroscopic procedures in women. Urology. 1988; 32: 529-31.

9. Tiselius HG, Alken P, Buck C, Gallucci M, Knoll T, Sarica K, et al.: Guidelines on Urolithiasis. EAU update series. 2008: 1-128.

10. World Health Organization Obesity: preventing and managing the global epidemic. Geneva: WHO, 1997.

11. Dindo D, Demartines N, Clavien PA: The Clavien-Dindo classification of surgical complications. Ann Surg. 2004; 244: 931-7.
12. Biring MS, Lewis MI, Liu JT, Mohsenifar Z: Pulmonary physiologic changes of morbid obesity. Am J Med Sci. 1999; 318: 293-7.

13. Steele D, Marshall V: Percutaneous nephrolithotomy in the supine position: a neglected approach? J Endourol. 2007; 21: 1433-7.

14. Shoma AM, El-Kenawy MR, Eraky I, El-Kappany HA, Ghoneim MA: One stage percutaneous nephrolithotomy (PCNL) in supine and prone positions: a comparative study. $\mathrm{Br} \mathrm{J}$ Urol (2000); 86 (suppl 3): 214.

15. Manohar T, Jain P, Desai M: Supine percutaneous nephrolithotomy: Effective approach to high-risk and morbidly obese patients. J Endourol. 2007; 21: 44-9.

16. Ng MT, Sun WH, Cheng CW, Chan ES: Supine position is safe and effective for percutaneous nephrolithotomy. J Endourol. 2004; 18: 469-74.

17. LeRoy AJ, Williams HJ Jr, Bender CE, Segura JW, Patterson $\mathrm{DE}$, Benson RC: Colon perforation following percutaneous nephrostomy and renal calculus removal. Radiology. 1985; 155: 83-5.

18. Hopper KD, Sherman JL, Luethke JM, Ghaed N: The retrorenal colon in the supine and prone patient. Radiology. 1987; 162: 443-6.

19. 19. Reddy PK, Hulbert JC, Lange PH, Clayman RV, Marcuzzi $A$, Lapointe $S$, et al.: Percutaneous removal of renal and ureteral calculi: experience with 400 cases. J Urol. 1985; 134: 662-5.

20. Segura JW, Patterson DE, LeRoy AJ, Williams HJ Jr, Barrett DM, Benson RC Jr, et al.: Percutaneous removal of kidney stones: review of 1,000 cases. J Urol. 1985; 134: 1077-81.

Correspondence address: Dr. Mohamed Esmat Department of Urology Ain Shams University, Cairo, Egypt Khalifa El-Maamon st, Abbasiya sq., Cairo Post Code 11566, Cairo, Egypt Fax: + 2022 690-4430

E-mail: m_esmat_2000@yahoo.com 